\title{
Transient Recovery Voltage Requirements in 550 kV Transmission Systems in THAILAND
}

\author{
H. Kajino, K, Kamei, H. Ito \\ Mitsubishi Electric Corporation, Japan
}

\begin{abstract}
Transient Recovery Voltage (TRV) requirements for UHV and EHV circuit breakers were investigated with the simple radial and meshed network models by CIGRE WG A3.28 and it was confirmed that the CIGRE network models could provide the TRV behaviours effectively using the system and equipment parameters in a national project [1], [2], [3]. The method with the simple radial model was applied to evaluate TRV in $550 \mathrm{kV}$ transmission systems in Thailand and the TRVs were compared with the results calculated in actual $550 \mathrm{kV}$ transmission systems. Furthermore, the influences of various system and equipment parameters on TRV requirements for different fault interrupting conditions such as bus terminal fault (BTF), long-line fault (LLF) and transformer limited fault (TLF) were investigated in detailed. TRV evaluation with the CIGRE network models was also confirmed as an effective method to evaluate TRV requirements for different interruption conditions in Thailand.
\end{abstract}

Keywords-circuit breaker; transient recovery voltage; radial and meshed networks; long line fault; bus terminal faults.

\section{INTRODUCTION}

Transient Recovery Voltage (TRV) requirements in the $550 \mathrm{kV}$ transmission systems in Thailand were investigated with the CIGRE network models developed by CIGRE WG A3.28 [1], [2], [3], [4], [5]. The WG A3.28 investigated and reported TRV requirements for different fault interrupting conditions such as bus terminal fault (BTF), long-line fault (LLF) and transformer limited fault (TLF) with UHV and EHV circuit breakers in different system and equipment parameters requested by IEC SC17A. The TRV investigations provided various influences of network topology (radial, meshed, power flow, shunt and series compensation) as well as specific systems design issues (transposition, height of towers and conductors, secondary arc extinction, line length, double versus single circuit $\mathrm{OH}$-lines, tower configurations, application of MOSA), fault conditions (single and multiphase faults, distance to fault, fault clearing pole, parallel circuit, earth resistivity) and other switching duties (unloaded line switching, healthy phase switching). The reports were published in the CIGRE Technical Brochure 570 titled with Switching Phenomena for EHV and UHV Equipment. In this paper, TRV evaluation with the CIGRE radial network model was applied to evaluate TRVs in actual $550 \mathrm{kV}$ transmission systems in Thailand.

\author{
K. Anantavanich, N. Paensuwan,
} S. Chareonsrikasem

Electricity Generating Authority of Thailand, Thailand

The influence of various system and equipment parameters on TRV was also described.

II. TRV CALCULATED IN THE CIGRE RADIAL

NETWORK MODEL USING SYSTEM AND EQUIPMENT PARAMETERS FOR 550KV TRANSMISSION SYSTEMS IN THAILAND.

The radial network model for TRV evaluation reported in CIGRE TB 570 has four power sources and three double-circuit transmission lines of 120, 240 and $360 \mathrm{~km}$ lengths, respectively as shown in Figure 1. In TRV analysis, a fault location was provided every $120 \mathrm{~km}$ along the $360 \mathrm{~km}$ transmission line between B S/S and D $\mathrm{S} / \mathrm{S}$ ( $\mathrm{S} / \mathrm{S}$ is an abbreviation of substation). Each fault can provides TRVs corresponding to BTF and LLF conditions using the system and equipment parameters applied to $550 \mathrm{kV}$ transmission systems in Thailand. The voltage distributions in the network model were checked and adjusted before TRV evaluation under a no-load condition providing the short circuit interrupting current at the bus terminal in the lower voltage systems to be $50 \mathrm{kA}$ (the maximum breaking current). Even under the no-load condition, the Ferranti effect increases the voltage at the remote end. Therefore, voltages at the remote $\mathrm{S} / \mathrm{S}$ are slightly reduced not to exceed the maximum voltage by reducing the system voltage in the lower voltage systems by about $5 \%$.

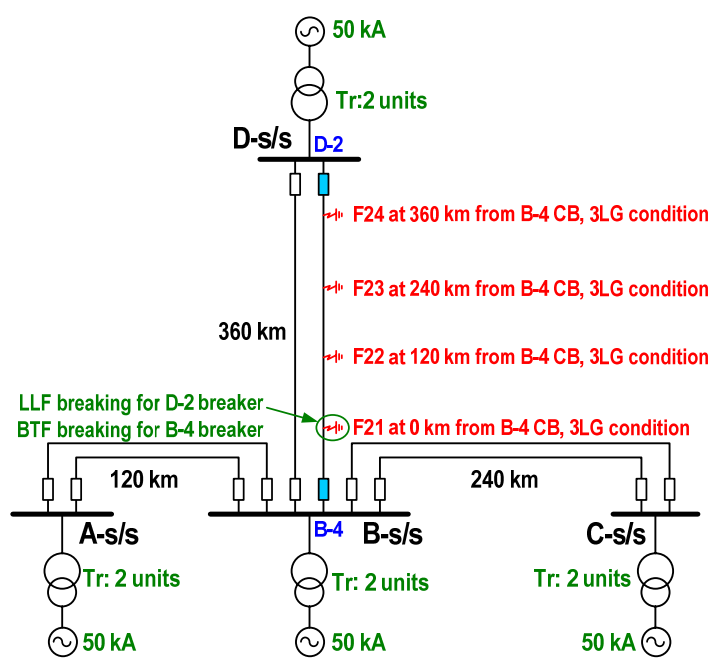

Figure 1. Radial CIGRE network model for TRV analysis 
Figure 2 shows typical TRV peaks and rate of rise of recovery voltages (RRRVs) calculated for BTF and LLF conditions using the system and equipment parameters in Thailand. Most of the TRV peaks and RRRVs are covered by the TRV requirements for the test duties T10, T30, T60 and T100 stipulated in the IEC Standard 62271-100. Several TRV peaks corresponding to LLF conditions exceed by about $4 \%$ (uc= $=1071 \mathrm{kV}$ at maximum) the

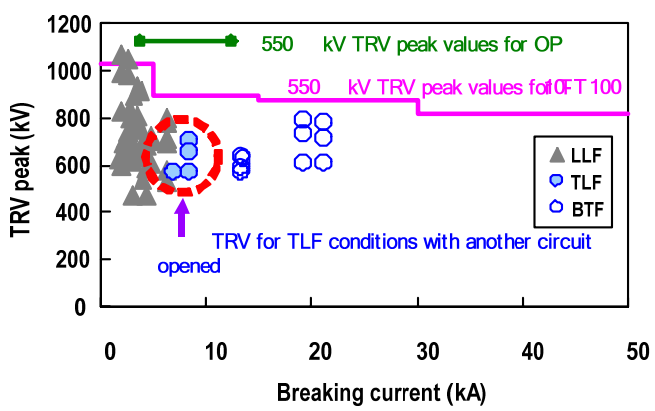

(a) TRV peak standard value for $\mathrm{T} 10(\mathrm{Uc}=1031 \mathrm{kV})$ duty with the interrupting currents smaller than $5 \mathrm{kA}$ when a fault was generated at $360 \mathrm{~km}$ from the circuit breaker. However these TRV peaks can be covered by the TRV stipulated for the out-of-phase duty $(\mathrm{Uc}=1123 \mathrm{kV})$. Higher RRRVs were also expected for TLF conditions when another circuit is opened. However, the calculated RRRVs can be covered by the standard values.

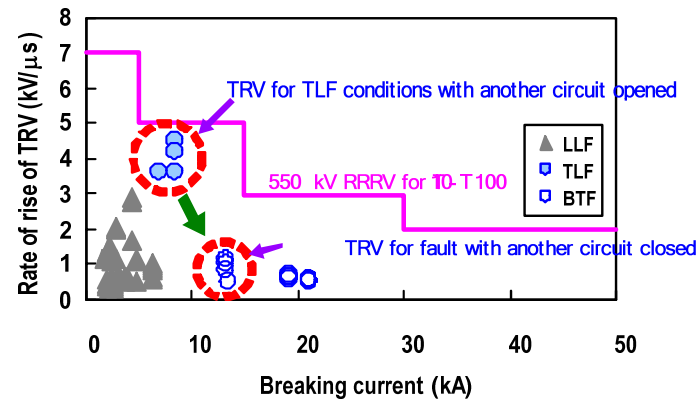

(b)RRRV

Figure 2. TRV for BTF and LLF conditions in the $550 \mathrm{kV}$ radial network model

\section{TRV IN $550 \mathrm{KV}$ ACTUAL TRANSMISSION SYSTEMS IN THAILAND}

Thailand network extends from north to south over $2000 \mathrm{~km}$ and the major electricity demands are concentrated in the middle of the land in the neighborhood of the capital city of Bangkok. While the main hydro power generations are located in the north remote boarder and the main thermal power generation are located in the south remote boarder. The $550 \mathrm{kV}$ transmission systems feature a combined nature of radial and meshed networks.

TRV requirements in $550 \mathrm{kV}$ actual transmission systems in Thailand were investigated in order to compare with the TRV results calculated in the radial network model. The actual $550 \mathrm{kV}$ transmission systems consist of 10 substations shown in Figure 3. TRVs corresponding to different fault interrupting conditions were calculated with an EMTP (Electro Magnetic Transients Program). The voltage distributions in the network model were adjusted before the TRV evaluation under a no-load condition providing the short circuit interrupting current at the bus terminal in the lower $(230 \mathrm{kV})$ voltage systems to be 30 $\mathrm{kA}$, which corresponds to $60 \%$ of the maximum breaking current, considering the actual fault currents. The Ferranti effect increases the voltage at the remote end. Therefore, voltages at the remote $\mathrm{S} / \mathrm{S}$ are slightly reduced not to exceed the maximum voltage by reducing the system voltage of $230 \mathrm{kV}$ systems in the lower networks by about $5 \%$.

The DC time constant in fault currents for the $230 \mathrm{kV}$ systems was given by $75 \mathrm{~ms}$. The amplitude factor, $\mathrm{K}_{\mathrm{f}}$ is 1.4 and the first pole to clear factor, $\mathrm{K}_{\mathrm{pp}}$ is 1.3 when the short-circuit current exceeds $30 \mathrm{kA}$. While $\mathrm{K}_{\mathrm{f}}$ is 1.5 and $\mathrm{K}_{\mathrm{pp}}$ is 1.3 , when the short-circuit current is above $15 \mathrm{kA}$ and lower than $30 \mathrm{kA}$. In the analysis, the generator voltage was provided in order that the power supply of the $230 \mathrm{kV}$ systems became $242 \mathrm{kV}$, without taking a powerflow into account, and the voltage on the secondary side of the generator transformer is $525 \mathrm{kV}$. The fault points were provided at 15 different locations assuming there phase lines to the ground (3LG) conditions shown in Figure 3.

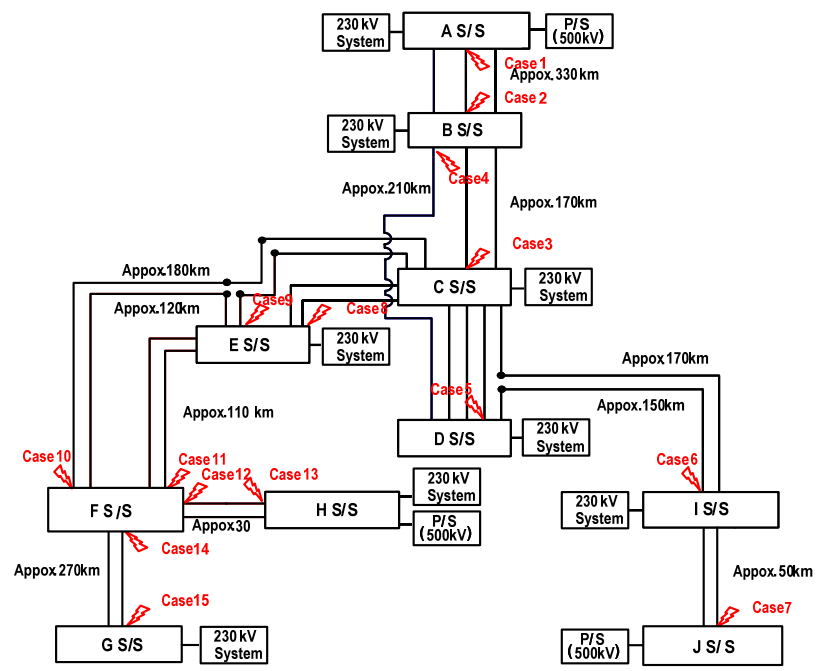

Figure $3.550 \mathrm{kV}$ actual transmission systems in Thailand 


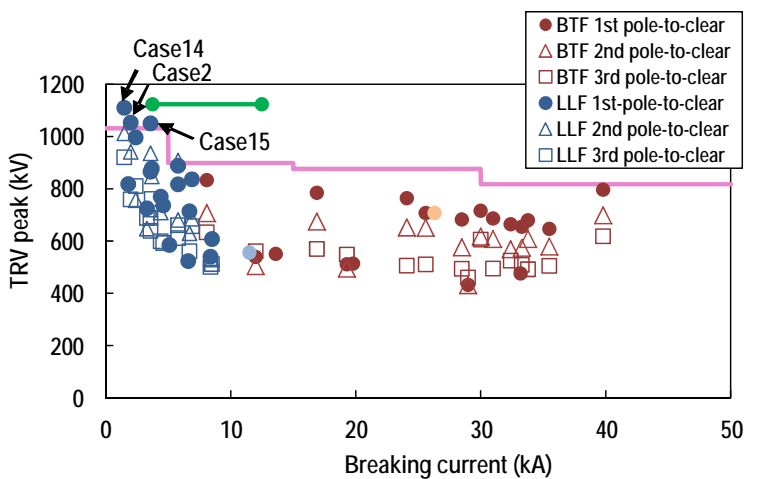

(a) TRV peak

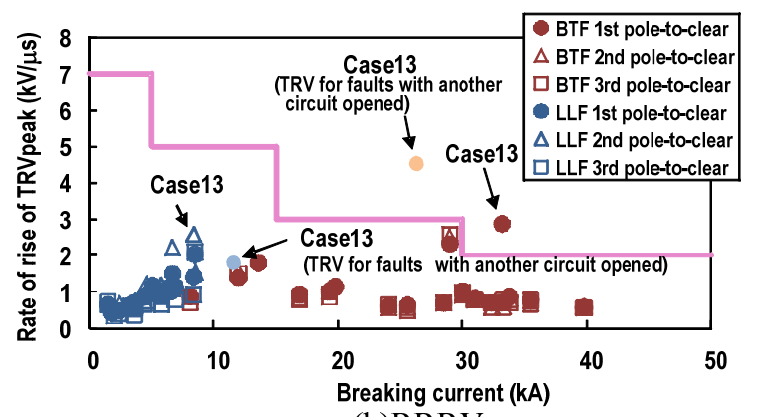

(b)RRRV

Figure 4. TRV peaks and RRRVs as a function of breaking currents for $\mathrm{BTF}$ and LLF conditions in $550 \mathrm{kV}$ transmission systems in Thailand

Figure 4 shows typical TRV peaks and RRRVs as a function of breaking currents for BTF and LLF conditions. Figure 5 shows typical TRV waveforms for BTF and LLF conditions in the actual $550 \mathrm{kV}$ transmission systems in Thailand. Most of the TRV peaks are covered by the standard values for the test duties T10, T30, T60 and T100 stipulated in the IEC 62271-100. Several TRV peaks for LLF conditions when a fault is located at 270 $\mathrm{km}$ and longer from the circuit breaker exceeds the standard values for the T10 duty, however, those are covered by the values for the out-of-phase duty $(1,123$ $\mathrm{kV})$.

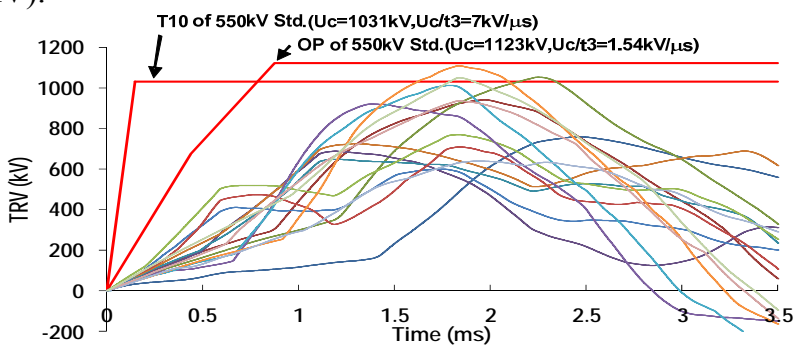

(a) TRV for LLF conditions at breaking currents of $5 \mathrm{kA}$ and less

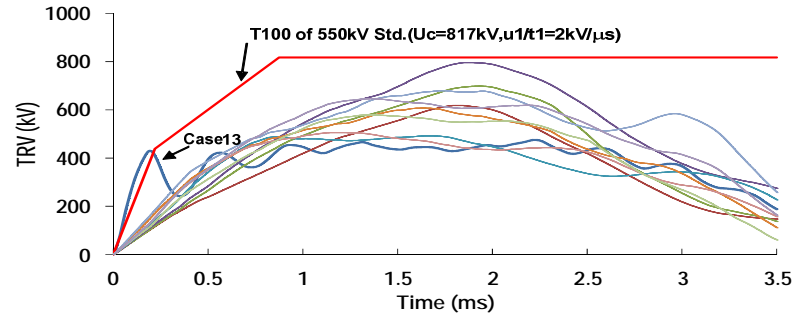

(b) TRV for BTF conditions at breaking currents from 30 $\mathrm{kA}$ and $50 \mathrm{kA}$

Figure 5. TRV waveforms for BTF and LLF conditions calculated in $550 \mathrm{kV}$ actual transmission systems in Thailand

Figure 6 shows the TRV waveform corresponding to the Case 15 at breaking current of $5 \mathrm{kA}$ or less, which exceeds the standard value for the T10 duty. TRV for LLF conditions may expect the severe peak when the instant of the TRV peak at the source side coincides with the timing of the TRV peak at the line side. In addition, TRV propagated from another line will be imposed on the TRV in the case of double circuit line. Furthermore, RRRVs corresponding to the Case 13 (similar to TLF interruption) exceeds the standard value for the T100 duty.

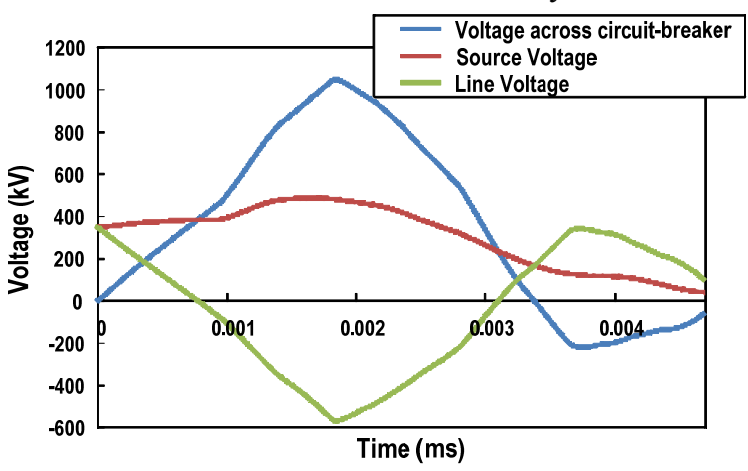

Figure 6. TRV waveform for LLF conditions

(Case15: line length of about $270 \mathrm{~km}$ and breaking current of $3.6 \mathrm{kA}$ )

RRRV can be given by the line impedance and the rate of rise of current at current interruption as given in the Equation. (1). The line impedance in case of another line opened becomes higher than when two lines of double circuit are closed, which results in higher rate of rise of voltage.

$$
\text { RRRV; dv/dt=Ze } \times \text { di } / \mathrm{dt}=\mathrm{Ze} \times \omega \times \sqrt{ } 2 \times \mathrm{I}
$$

When an interrupting phase order in the case of LLF conditions was considered, RRRV is higher for the second pole to interrupt than that for the first pole to interrupt. It is considered that the primary windings of the transformer have a delta connection, which reduces the zero-phase impedance in compared with the positive phase impedance.

TRV peaks and RRRVs dependence on the distance from a fault point to the circuit breaker are summarized in the Figure 7. The maximum TRV appears at $270 \mathrm{~km}$ from the circuit breaker to a fault, which corresponds to LLF 
conditions and severe RRRVs are also observed when a fault occurs close to the bus terminal, which corresponds to TLF conditions.

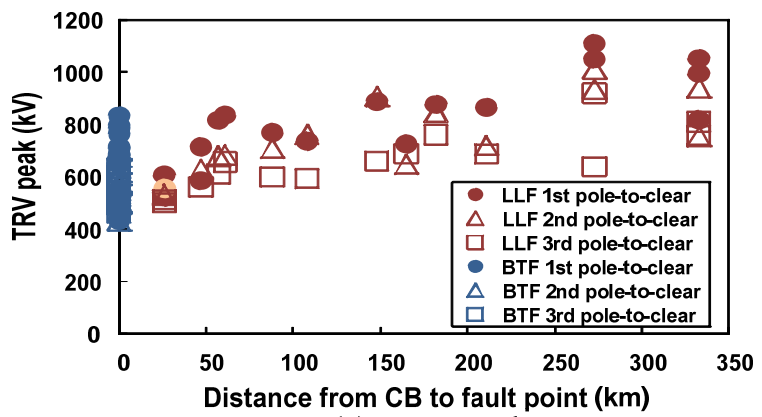

(a) TRV peak

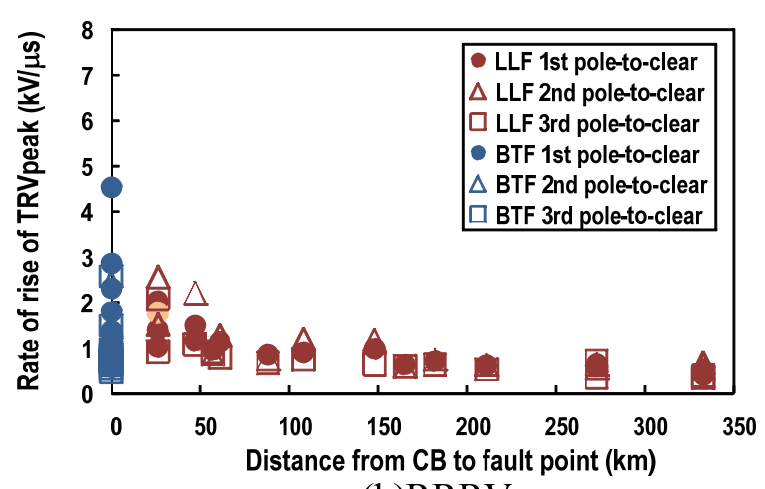

(b)RRRV

Figure 7. TRV peaks \& RRRVs dependence on the distance from CB to a fault point

\section{CONCLUSION}

TRVs for different fault interrupting conditions were evaluated with the radial CIGRE network model using the system and equipment parameters in Thailand. These TRVs were compared with the results calculated in actual $550 \mathrm{kV}$ transmission systems in Thailand. The TRV results calculated both in the CIGRE radial network model and in the $550 \mathrm{kV}$ transmission systems in Thailand, show that the TRV peak values or RRRVs for BTF and LLF conditions may exceed the standard values for T10, T30 duties but may not exceed the standard values for out-of-phase duty stipulated in the IEC 62271100 .

\section{REFERENCES}

[1] CIGRÉ technical Brochure 570, Feburuary 2014, "Switching Phenomena for EHV and UHV equipment", by CIGRE WG A3.28

[2] CIGRÉ Technical Brochure 362, December 2008, "Technical Requirements for Substation Equipment exceeding $800 \mathrm{kV}$ "

[3] CIGRÉ Technical Brochure 456, April 2011, "Background of Technical Specifications for Substation Equipment exceeding 800 $\mathrm{kV}$ AC"

[4] IEC Std 62271-100, 2nd edition, 2012, "High-voltage switchgear and controlgear - Part 100: Alternating-current circuit-breakers"

[5] A.L.J. Janssen, D. Dufournet, H. Ito, H. Kajino, Y. Yamagata, M. Kosakada, "Transformer Limited Fault Duties for UHV and EHV", CIGRÉ UHV Colloquium New Dehli 2013 , 